\title{
Pilates versus resistance exercise on the serum levels of hs-CRP, in the abdominal circumference and body mass index (BMI) in elderly individuals
}

\author{
Pilates versus exercício resistido nos níveis séricos da PCR-as, na \\ circunferência abdominal e IMC em idosos
}

Maria Dida Silva Pestana ${ }^{1,2^{*}}$, Eduardo Martins Netto ${ }^{1}$, Manuella Castro Silva Pestana ${ }^{1}$, Vitor Silva Pestana ${ }^{1}$, Maria Isabel Schinoni ${ }^{1}$

ORIGINAL ARTICLE | ARTIGO ORIGINAL

\begin{abstract}
Recent studies have shown that the elderly exhibit a subclinical state of inflammation associated with increased adipose tissue and several comorbidities. To compare the effects of mat Pilates based exercises and resistance exercise on the serum levels of reactive $C$ protein of high sensitivity (hs-CRP), in the abdominal circumference (AC) and the body mass index (BMI) in the elderly. It is a randomised clinical trial with a sample of 78 elderly individuals (median age 69 years). The active independent variable investigated was nature of treatment intervention (Pilates mat based exercises vs resistance exercise), and the dependent variables were hs-CRP level, AC and BMI. The statistical analysis used Wilcoxon signed rank and Mann-Whitney tests. The correlation between the continuous variables was assessed using Spearman's coefficient of correlation. The data were analysed using SPSS software version 17.0, and probability values lower than 5\% $(p<0.05)$ were considered statistically significant. Mat Pilates based exercises exhibited reductions in serum hs-CPR level (Wilcoxon signed rank test; $z=-2.466, \mathrm{p}=0.01$ ), BMI (Wilcoxon signed rank test; $z=-3.295, p=0.001$ ) and AC (Wilcoxon signed rank test; $z=-3.398, p=0.01$ ). Mat Pilates based exercises promoted a significant reduction of the serum hs-CRP levels and anthropometric measurements in elderly individuals.
\end{abstract}

Keywords: Exercise therapy. Aging. Inflammation. Central obesity.

RESUMO

Pesquisas recentes demonstram que os idosos apresentam um estado subclínico de inflamação, associado ao aumento de tecido adiposo e a várias comorbidades. Comparamos os efeitos de exercícios baseados Pilates mat e exercício resistido sobre os níveis séricos de proteína $\mathrm{C}$ reativa de alta sensibilidade (PCRhs), na circunferência abdominal (CA) e no índice de massa corporal (IMC) em idosos. Trata-se de um ensaio clínico randomizado, com amostra de 78 idosos (idade mediana de 69 anos). As variáveis independentes ativas estudadas foram o Pilates mat e exercício resistido; as variáveis dependentes foram a PCR-hs, CA e IMC. A análise estatística utilizada foi baseada em testes não paramétricos de Wilcoxon signed rank and Mann-Whitney. A correlação entre as variáveis contínuas foi avaliada por meio do coeficiente de correlação de Spearman, os dados foram analisados pelo programa SPSS, versão 17.0; a probabilidade do valor inferior a $5 \%$ foi considerada estatisticamente significante. Exercícios baseados em Pilates mat exibiram reduções nos níveis séricos de PCR-hs (Wilcoxon signed rank; $z=-2.466, p=0.01$ ), IMC (Wilcoxon signed rank; $z=-3.295, p=0.001$ ) e AC (Wilcoxon signed rank; $z=-3.398, p=0.01$ ). Exercícios baseados em Pilates mat promoveram uma redução significativa dos níveis séricos de PCR-hs e medidas antropométricas em idosos.

Palavras-chave: Terapia por Exercício. Envelhecimento. Inflamação. Obesidade Central.

\footnotetext{
Manuscript received at March 20 $0^{\text {th }} 2015$; Accepted at January $1^{\text {st }} 2016$

${ }^{1}$ Instituto de Ciências da Saúde, Universidade Federal da Bahia, Salvador da Bahia, BA, Brasil;

${ }^{2}$ Universidade Estadual do Sudoeste da Bahia, Jequié, BA, Brasil.

* Autor correspondente: Rua Conselheiro Correia de Menezes, 266/AP: 502, Ed M. Horto Renaissance, Horto Florestal, Salvador-Bahia,Brazil CEP: 40295030

E-mail: didapestana@yahoo.com.br didapestana@clinicasempre.com.br
} 


\section{INTRODUCTION}

Recent studies have shown that elderly individuals exhibit a pro-inflammatory condition characterised by a slightly elevated inflammation level that is much lower than that observed in acute inflammation. It is believed that lifestyle factors and chronic pathological conditions, such as increased adipose tissue, Type 2 diabetes, coronary artery disease, osteomuscular disease, arterial hypertension, altered lipid profile, and insulin resistance might be associated with this inflammatory state (Lakka et al., 2005).

Systemic low grade inflammation has been linked with obesity and the decline in skeletal muscle related to age (Licastro et al., 2005; Mavros et al., 2014; Sasaki et al., 2007). Nicklas and Brinkley (2009) reported, on a review article, that cross-sectional studies have shown an inverse relationship between muscle mass, muscle strength and other measures of physical function, with inflammation in the elderly. These studies have shown that elevated levels of Creactive protein of high sensitivity (hs-CRP) and interleukin 6 (IL-6) are associated with poorer motor function in the elderly (Nicklas \& Brinkley, 2009).

With the aging process, the number of cells comprising the body decreases, the activity of each of the cells is deteriorates, resulting in the fragility syndrome, which occurs with the aging process and is associated with decline in neuromuscular, and cardiovascular systems. Thus, physical adaptability is gradually lost, resulting in the decrease in the ability to perform daily activities, which puts individuals at risk of disability, loss of independence and hospitalization (Cadore, Pinto, Bottaro, \& Izquierdo, 2014; Hyun, Hwangbo and Chae-Woo Lee, 2014). So as to prevent neuromuscular and cardiovascular decline associated with aging and also to prevent and treat fragility syndrome, strength and resistance training seems to be an effective strategy to improve muscle hypertrophy, strength and potency, as well as resistance performance. In contrast, the resistance formation induces central and peripheral adjustments that improve cardiovascular function, and the ability of skeletal muscle to generate energy through oxidative metabolism. Thus, it is believed that a combination of strength and endurance training in the elderly is the most effective way to improve cardiac and neuromuscular function and therefore to preserve the functional capacity (Cadore et al., 2014).

Resistance exercises that are performed against some form of gradable resistance to muscle contraction, and in most cases resistance are weights, is associated with the reduction of risk of diseases related to low-grade inflammation, such as cardiovascular disease and type 2 diabetes. The reduction in hs-CRP with training could be associated, among others, to reduced fat mass or specifically with waist circumference that usually occurs with training. (Calle \& Fernandes, 2010).

The literature reviews performed by Licastro et al. (2005) and Sasaki et al. (2007) reported data suggesting that high levels of inflammatory factors serve as markers of obesity and abdominal obesity associated with aging. Those authors reported that adipose tissue exhibits intense endocrine and metabolic activity and that proinflammatory cytokines and hs-CRP are some of the substances secreted by adipocytes.

Chronic subclinical inflammation has been associated with increased levels of several cytokines and hs-CPR, which has been reported in several clinical studies as the main marker of inflammation (Cesari et al., 2004; Lakka et al., 2005; Lin et al., 2010; Sasaki et al., 2011). Lin et al. (2010) studied the correlation between hsCRP level and body mass index (BMI) and abdominal circumference (AC) in a Taiwanese population. The sample included individuals aged 40 to 88 years old, and the results showed that high hs-CRP levels correlated with the percentage of fat in both males and females.

Stewart et al. (2007) performed a comparative study of the influence of a 12-week aerobic exercise program associated with resistance training on hs-CRP and inflammatory cytokine levels in elderly and young individuals to establish whether training induces hs-CRP and cytokine changes in several age ranges. The serum hs-CRP level decreased with training in the inactive groups but did not differ in the active groups after training. 
Nicklas and Brinkley (2009) performed an intervention (combining resistance exercise to aerobic exercise) study in which the levels of inflammation marker production in individuals aged 70 to 80 years old were assessed. The intervention consisted of strength, balance, aerobic, and flexibility training. After 12 months of intervention, the BMI did not change; however, hs-CRP levels exhibited a significant decreasing tendency.

Kim, Kim, and Kim (2014) analyzed the impact of the Pilates method in the metabolism of lipids, as well as the mRNA changes of inflammatory cytokines, body mass index and body fat. This study used the Pilates method for 8 weeks in young women, aged 20 years. Analysis of Body Mass Index showed a decrease in both control and exercise groups, but without significant difference. IL-6 mRNA in blood analysis showed no effect of interaction vs time.

Kopitzke (2007) and Hyun, Hwangbo, and Chae-Woo Lee (2014) reported that the method may be suitable for elderly, since this population may have sedentary life and their sensory system will operate with less effectiveness; the body center - consisting of abdominal muscles, paraspinal and pelvic floor - becomes weak with the gradual weakening of the stabilizing muscles of the hip and shoulder. Thus recovering the lost flexibility, and the ability to move properly with good support and postural alignment, thereby preventing the high rate of occurrences of falls and fractures.

Joseph Pilates, the creator of the Pilates method, observed that early mobilisation during rehabilitation resulted in shorter convalescence. The modern approach of the Pilates method posits that the body is an integrated unit and aims at establishing control of the trunk muscles, which are defined as a 'powerhouse' (Segal, Hein, \& Basford, 2004). Thus, it is believed that when the trunk is stabilised, limb motions can be performed with greater efficiency and that a strengthened and stable powerhouse can lead to improved health (Kaesler, Mellifont, Kelly, \& Taaffe, 2007; Sekendiz, Altun, Korkusuz, \& Akın, 2007). Conversely, an unstable trunk might increase stress at the intervertebral joints, thus favouring the degeneration of those segments and the consequent appearance of diseases (Kopitzke, 2009; Muscolino \& Cipriani, 2004). The principles of Pilates emphasise the improvement of breathing, concentration, control, axial elongation, and flexibility, which are associated with increased strength (Miranda \& Morais, 2006; Panelli \& De Marco, 2006).

Studies, which have been currently conducted, refer to the therapy by exercise in abdominal obesity and inflammation markers in adults and elderly. In these studies the protocols which are used employ resistance exercise associated with aerobic exercise. However, it is difficult to identify how effective of the used method, since it cannot be dissociated from the confounding effects of resistance exercises combined to aerobic exercises.

The therapy by exercise to the elderly has been proposed as prevention and treatment of disabling events, chronic diseases and risk factors. However, individual differences related to functional capacity may limit the performance of the elderly in the practice of physical activity. Thus, in order to guide the exercise prescription to the elderly, it seems important to identify the most effective combination of the variables in the protocols (ie, intensity, duration, weekly frequency and exercise series) to promote neuromuscular and cardiovascular adaptations in the elderly.

No study relating the effects of Pilates mat based exercises on serum hs-CRP levels and fat measurements in the elderly could be located in the literature. The available studies on resistance exercise and inflammation do not clearly state which techniques might be appropriate for the elderly because rehabilitation professionals must assess the factors that might make comorbidities worse before they can prescribe exercise. Therefore, the present study aimed to analyze whether Ground Pilates reduces serum levels of C-reactive protein, abdominal circumference and body mass index in the elderly more effectively than resistance exercises. In order to deny the null hypothesis, which claims that Ground Pilates does not reduce more effectively than resistance exercises, the serum levels of Creactive protein, the abdominal circumference and the body mass index in the elderly. 


\section{METHOD}

\section{Study design and participants:}

This study was a randomised clinical trial in which the sample was chosen by convenience. Seventy eight individuals aged 60 to 85 years old were selected. Their median age was 69 years old, 89.7\% were female (median $\mathrm{BMI}=25.22$ and $\mathrm{AC}=98.0$ ), and $10.3 \%$ were male (median $\mathrm{BMI}=23.8$ and $\mathrm{AC}=96.0$ ).

The sample was paired by sex and age range, a drawing between peers was carried out and divided by random assignment into two experimental groups: Group Pilates mat based exercises [GP], $\mathrm{n}=39$ and Group Resistance Exercise [GR], $\mathrm{n}=39$.

Figure 1 depicts the screening process and the follow-up of the randomisation process. Two patients in GP dropped out because of disease, one exhibited depression, two had to assist ill relatives, four discontinued the training, four trained with irregular frequency, and the data of another three were lost. In GR, three patients dropped out due to diseases or surgery, six discontinued the training, six trained with irregular frequency, and the data of two were lost. Thus, the final sample comprised 23 individuals in GP and 22 in GR.

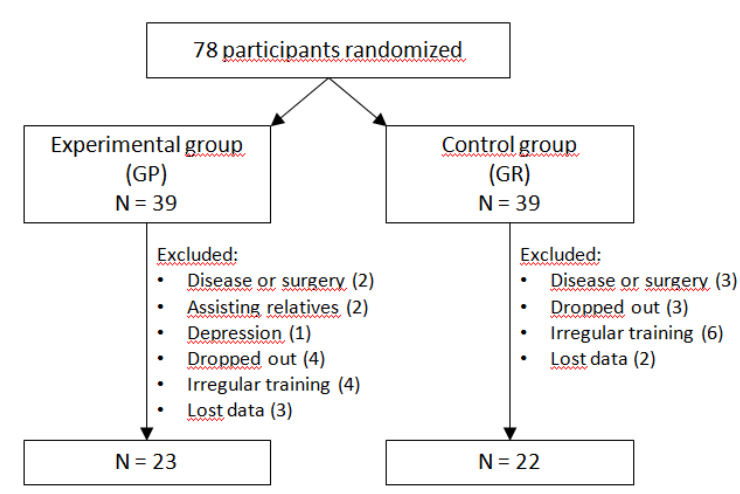

Figure 1. Screening and follow-up of the randomisation process

As inclusion criteria, the sample included elderly individuals who did not practice exercises regularly, who were receiving regular medical care, who underwent electrocardiogram, had medical clearance to practice moderate exercise, and had intact cognitive functions. Patients dependent on insulin and with decompensated heart disease were excluded from the study.
The present study complied with the ethical norms established by the Declaration of Helsinki and Resolution 196/96 of the National Health Council. The study protocol was approved by the Research Ethics Committee of Climério de Oliveira Maternity Hospital - Federal University of Bahia, Protocol 175/2010, and the participants signed an informed consent form.

\section{Instruments}

The volunteers completed a sociodemographic questionnaire and the Mini Mental State Examination (MMSE) (Almeida, 1988). Baseline measurements of hs-CRP were performed and analyzed using nephelometry (a specific device that measures the turbidity is used and measures the diffraction [deviation] of light passing through a solution containing immune complexes).The results were classified according to recommended guidelines, i.e., low: $<1.0$ $\mathrm{mg} / \mathrm{L}$, moderate: $1.0-3.0 \mathrm{mg} / \mathrm{L}$, and high: $>3.0$ $\mathrm{mg} / \mathrm{L}$ (Lakka et al., 2005). The classification for the waist circumference has been recommended according to the degree of risk for cardiovascular disease: increased risk for females (abdominal circumference- AC $>80 \mathrm{~cm}$ ) and males (AC $>94$ $\mathrm{cm})$ and very high risk for females $(\mathrm{AC}>88 \mathrm{~cm}$ ) and males $(A C>102 \mathrm{~cm}$ ) (McArdle, Katch, \& Katch, 2008, p. 799). The cut-off points selected for body mass index -BMI were low weight (BMI $<18.5$ ), normal weight (BMI 18.5 to 24.99), overweight (BMI 25 to 29.99), and obesity ( $\geq$ $30.00)$, as recommended by the World Health Organization - WHO (2008). A single trained evaluator carried out the anthropometric assessment. Abdominal circumference was measured with a flexible and inelastic tape (Medjet fiberglass tape), taking care not to be compression of tissues. The abdominal girth was measured in four distinct anatomical locations: umbilical level, and the smallest waist between the thorax and the hip; immediately above the iliac crests and at the midpoint between the iliac crest and the last rib. The measurements were performed at the end of the expiring time. Abdominal measurements were taken in duplicate and calculated their respective averages. When there was difference $>1 \mathrm{~cm}$ between the two measurements, a third measure 
was performed, being used the two closest values. The body mass index was calculated from the formula expressed in $\mathrm{kg} / \mathrm{m}^{2}$ (Vasques et al., 2009):

$$
B M I=\frac{w e i g h t}{h^{2} i g h t^{2}}
$$

\section{Procedures}

The heart rate of the participants at rest was measured considering the heart beats per minute and maximum heart rate (MHR); it was found, according to the average maximum effort (10$\mathrm{RM}$ ), during the training session, that it was a moderate exercise (Polito \& Farinatti, 2003). The intensity of training was moderate. For that purpose, the maximum heart rate at 60 to $70 \%$ training was taken into account using the formula 220 minus the individual's age (McArdle et al., 2008, p. 901). Heart rate was measured via a personal heart rate monitor, which was used between the last and next-to-last repetitions of the series during which the workload approached maximum strength.

The exercises used for the repetition maximum test were: femur arches and femur circles, circles with one leg, the hundred, swimming, stretching a leg, series of side elevation of the legs, mini squats against the wall/associate with arms and elastic bands, half pointe with one leg, sit/stand; 10 repetitions with interval of 30 seconds were performed between series. Measures of heart rate (HR) were taken in duplicate and had their averages calculated. When there were differences between the two measures, a third measure was performed, being used the two closest values. According Mcardle, Katch, and Katch (2008, p. 492) the error in estimating the maximum volume of oxygen $\left(\mathrm{VO}_{2} \mathrm{max}\right)$ percentage from the percentage of maximum heart rate (HR max) or vice versa, is equal to approximately $8 \%$.

Therefore, simply monitoring your heart rate to estimate the stress for the year or percentage $\mathrm{VO}_{2} \max$ within the range of a given error is enough. In the elderly, most studies have reported that the concurrent training induced strength adaptations such as using two sessions per week of each modality (i.e., strength and endurance). However, three times per week of concomitant formation can result in an interference effect in this population. Furthermore, the course of strength development over a period of time, the concomitant formation can be influenced by the frequency of training per week. These authors showed that after 16 weeks of training, similar gains of lower body strength were observed, suggesting that a minimum weekly frequency of concurrent training can promote an ideal stimulus for strength gains in previously untrained elderly (Calle \& Fernandes, 2010).

According to Mcardle et al. (2008, p. 525528), the purposes of resistance training for seniors, focus on maintaining and if possible increasing muscle strength and endurance, in order to improve the overall health and profile of physical fitness. Thus, the unique series of diversified exercises are recommended to be performed between 8-15 maximum repetitions (MR) in a minimum of twice weekly. The power training should apply the strategy capable to improve muscle strength, besides including lighter loads, and should be performed in a more rapid contraction speed, by using periods of rest 2-3 minutes between sets.

The protocols were divided into stages performed for 60 minutes twice per week for a total of 20 weeks. The materials used in the resistance exercise programme were weights, ankle weights, mats, and chairs. For the Pilates mat based exercises programme, elastic bands, mats, and chairs were used. The exercises included the following activities:

\section{Resistance exercise protocol}

Elongation and strengthening of the following muscle groups were performed: extensors and flexors of the knees, ankles, elbows, shoulders, and hips; hip and shoulder abductors and adductors; shoulder lateral and medial rotators; and abdominals.

Stage 1 (two weeks): Open kinetic chain exercises were performed without additional load in series of 10-RM with three-second contractions (c-03) and relaxations ( $\mathrm{r}-03)$. 
Stage 2 (six weeks): Open kinetic chain exercises with $1-\mathrm{kg}$ weights and ankle weights in series of 10-RM, c-03, and r-03.

Stage 3: Open and closed kinetic chain exercises with $1-\mathrm{kg}$ weights and ankle weights and abdominal strengthening exercises were performed in series of 10$\mathrm{RM}, \mathrm{c}-03$, and $\mathrm{r}-02$; at the end of each series, 10- RM of rapid movements of small amplitude were added.

Stage 4 (six weeks): Open and closed kinetic chain exercises with 1-kg weights and ankle weights and abdominal strengthening exercises in series of 10$\mathrm{RM}, \mathrm{s}-03$, and $\mathrm{r}-01$. At the end of each series, a 1-RM contraction and c-10 was added.

\section{Pilates mat based exercises protocol}

Stage 1 (two weeks 10- RM): Training in the basic principles of the Pilates method took place, with dissociation exercises to preserve and gain mobility and flexibility in the limbs and exercises to strengthen the limb muscles and stabilise the spinal column.

Supine decubitus: Three-dimensional diaphragmatic breathing, dissociation and stabilisation of the scapulae, arm circles, recruitment of the pelvic floor, pelvic positioning, recruitment of the transverse abdominal muscle, hip loosening, supine scapular mobilisation, and preparation for breast swimming.

Sitting: Femur arcs and circles, scissors with the arms, foot beating, and arm circles.

Stage 2 (six weeks; 10- RM):

Sitting: Elongations of the upper and lower limbs and paravertebral muscles, foot beating, femur arcs and circles, and sitting down/rising up. With the elastic band: scissors with the arms, arcs with the arms, horizontal abduction and adduction of the shoulders, brachial biceps movements, lateral and medial rotators of the shoulder, brachial triceps, large dorsal movements, and abduction and adduction of the hips.
Supine decubitus: Circles with one leg, femur arcs and circles, and bridge with stable spine. Lateral decubitus: Side-kick series.

Stage 3 (six weeks; 10- RM):

Supine and ventral decubitus: Femur arcs and circles, circles with one leg, the hundred exercise, swimming, elongation of one leg, and preparation for front support.

Lateral decubitus: Side-kick series.

Standing: Mini-squatting at the wall, combined with arm exercises with the elastic band.

Stage 4 (six weeks; 10- RM):

Supine and ventral decubitus: Femur arcs and circles, circles with one leg, the hundred exercise, swimming, elongation of one leg, and preparation for front support.

Lateral decubitus: Side-kick series.

Standing: Pliés, mini-squatting at the wall combined with arms and elastic bands, half-point with a single leg, and sitting down/rising up.

The series of abdominal exercises on the ground (stages 2, 3 and 4) were performed without breaks, in order to maintain the elevated heart rate within the parameters of moderate exercise (60-70\%).

\section{Statistical analysis}

The independent active variable investigated was nature of treatment intervention (Ground Pilates exercises and resistance exercise). The dependent variables were hs-CRP level BMI, and AC. Missing data was analysed for assessment of selection bias (data presented separately). The statistical analysis employed parametric and nonparametric tests, which were chosen based on graphical and statistical analysis (ShapiroWilk test, considering the reduced sample size). Tests were held to compare (post - pre)intervention variation and group difference (Pilates vs. resistance exercise). The correlation between continuous outcome variables was assessed using Spearman's coefficient of correlation. All data was analysed with ${ }^{\circledR}$ IBM SPSS software Version 17.0 and p-values lower than $5 \%(\mathrm{p}<0.05)$ were considered statistically significant. 


\section{RESULTS}

Table 1 describes the demographic and clinical characteristic of sample at baseline. The sample consisted of elderly patients with average age of $69.5 \pm 4.5$ (GP) vs $69.3 \pm 5.5$ (GR); being $78.3 \%$ of females (GP) vs $86.4 \%$ (GR) and $21.7 \%$ of males (GP) and $13.6 \%$ (GR). These individuals had the BMI of $25.7 \pm 3.9$ in GP and $26 \pm 5.6$ in GR. Female abdominal circumference over $88 \mathrm{~cm}$ represented $94.4 \%$ in the GP and $68.4 \%$ in the GR. The serum levels of hs-CRP were high ( $>3$ ) in $52.2 \%$ vs $54.5 \%$ in the GP in the GR, and moderate (1-3) in $47.8 \%$ in the GP and $45.5 \%$ in the GR.

Table 1

Demographic and clinical characteristic of sample at baseline

\begin{tabular}{|c|c|c|c|}
\hline Characteristics & Pilates $(\mathrm{N}=23)$ & Resistance $(\mathrm{N}=22)$ & Total $(\mathrm{N}=45)$ \\
\hline \multicolumn{4}{|l|}{ Age } \\
\hline Median & 71 & 69 & 70 \\
\hline Interquartile interval & $66-72$ & $64-73$ & $66-72$ \\
\hline Mean \pm standard deviation & $69.5 \pm 4.5$ & $69.3 \pm 5.5$ & $69.4 \pm 4.9$ \\
\hline \multicolumn{4}{|l|}{ Gender } \\
\hline Female, n (\%) & $18(78.3)$ & $19(86.4)$ & $37(82.2)$ \\
\hline Male, n (\%) & $5(21.7)$ & $3(13.6)$ & $8(17.8)$ \\
\hline \multicolumn{4}{|l|}{ Schooling } \\
\hline Illiterate, n (\%) & $5(21.7)$ & $12(54.5)$ & $17(37.8)$ \\
\hline Studied up to 4 years, n (\%) & $10(43.5)$ & $5(22.7)$ & $15(33.3)$ \\
\hline Studied 4 to 8 years, $\mathrm{n}(\%)$ & $3(13.0)$ & $2(9.1)$ & $5(11.1)$ \\
\hline Studied 8 or more years, n (\%) & $5(21.7)$ & $3(13.6)$ & $8(17.8)$ \\
\hline \multicolumn{4}{|l|}{ BMI $\left(\mathrm{kg} / \mathrm{m}^{2}\right)$} \\
\hline Mean \pm standard deviation & $25.7 \pm 3.9$ & $26.9 \pm 5.6$ & $26.3 \pm 4.8$ \\
\hline $18.5-24.9=$ normal weight, $\mathrm{n}(\%)$ & $10(43.5)$ & $9(40.9)$ & $19(42.2)$ \\
\hline $25.0-29.9=$ overweight, $\mathrm{n}(\%)$ & $9(39.1)$ & $4(18.2)$ & $13(28.9)$ \\
\hline$>30.0=$ obesity, $\mathrm{n}(\%)$ & $4(17.4)$ & $9(40.9)$ & $13(28.9)$ \\
\hline \multicolumn{4}{|l|}{ AC $(\mathrm{cm})$} \\
\hline & \multicolumn{2}{|c|}{ Female } & $98.8 \pm 12.9$ \\
\hline$<80, \mathrm{n}(\%)$ & $0(0.0)$ & $3(15.8)$ & $3(8.1)$ \\
\hline $80-87.9, \mathrm{n}(\%)$ & $1(5.6)$ & $3(15.8)$ & $4(10.8)$ \\
\hline 88 and over, $\mathrm{n}(\%)$ & $17(94.4)$ & $13(68.4)$ & $30(81.1)$ \\
\hline \multicolumn{4}{|l|}{ Male } \\
\hline$<94, \mathrm{n}(\%)$ & $1(20.0)$ & $1(33.3)$ & $2(25.0)$ \\
\hline $94-101.9, \mathrm{n}(\%)$ & $2(40.0)$ & $1(33.3)$ & $3(37.5)$ \\
\hline 102 and over, $\mathrm{n}(\%)$ & $2(40.0)$ & $1(33.3)$ & $3(37.5)$ \\
\hline \multicolumn{4}{|l|}{ hs-CRP (mg/L) } \\
\hline Median & 3.2 & 3.4 & 3.3 \\
\hline Interquartile interval & $2.2-5.0$ & $2.1-5.0$ & $2.1-5.0$ \\
\hline$<1=$ low, n (\%) & $0(0.0)$ & $0(0.0)$ & $0(0.0)$ \\
\hline $1-3=$ moderate, $\mathrm{n}(\%)$ & $11(47.8)$ & $10(45.5)$ & $21(46.7)$ \\
\hline$>3=$ high, $\mathrm{n}(\%)$ & $12(52.2)$ & $12(54.5)$ & $24(53.3)$ \\
\hline \multicolumn{4}{|l|}{ Comorbidities } \\
\hline Diabetes, n (\%) & $14(60.9)$ & $4(18.2)$ & $18(40.0)$ \\
\hline Hypertension, n (\%) & $19(82.6)$ & $15(68.2)$ & $34(75.6)$ \\
\hline Diabetes and hypertension, $\mathrm{n}(\%)$ & $13(56.5)$ & $4(18.2)$ & $17(37.8)$ \\
\hline No diabetes or hypertension, $\mathrm{n}(\%)$ & $3(13.0)$ & $7(31.8)$ & $10(22.2)$ \\
\hline
\end{tabular}

It has been shown that the Pilates mat based exercises was more effective than resistance exercise in reducing AC $(\mathrm{p}=0.004)$ and BMI $(\mathrm{p}$ $=0.007)$ (Table 2$)$.

In table 3 the result shows that there was no difference between the GR and GP methods, regarding the reduction of the levels of hs-CRP $(\mathrm{p}=0.158)$.
Table 2

Comparison of difference (post - pre)-intervention for $B M I$ and $A C$

\begin{tabular}{|c|c|c|}
\hline & BMI $\left(\mathrm{kg} / \mathrm{m}^{2}\right)$ & p value $^{\mathrm{a}}$ \\
\hline Pilates $(n=23)$ & $-0.79(-1.29--0.34)$ & \multirow{2}{*}{0.007} \\
\hline Resistance $(\mathrm{n}=22)$ & $0.08(-0.76-0.80)$ & \\
\hline \multicolumn{3}{|c|}{$\mathrm{AC}(\mathrm{cm})$} \\
\hline Pilates $(n=23)$ & $-4.00(-7.00--2.00)$ & \multirow{2}{*}{0.004} \\
\hline Resistance $(\mathrm{n}=22)$ & $-0.75(-4.00-0.00)$ & \\
\hline
\end{tabular}


Table 3

Comparison of difference (post - pre)-intervention for $h s-C R P$

\begin{tabular}{cccc}
\hline & hs-CRP (mg/L) & $\begin{array}{c}\text { Difference between } \\
\text { GP and GR } \\
\text { (mean and 95\% CI) }\end{array}$ & p value $^{\text {a }}$ \\
\hline $\begin{array}{c}\text { Pilates } \\
(\mathrm{n}=23)\end{array}$ & $-0.45 \pm 1.11$ & & \\
$\begin{array}{c}\text { Resistance } \\
(\mathrm{n}=22)\end{array}$ & $0.04 \pm 1.07$ & $0.49(-0.20-1.17)$ & 0.158 \\
\hline
\end{tabular}

All results are presented as mean \pm standard deviation.

${ }^{a}$ Independent sample $t$ test comparing differences (post-pre)intervention between GP and GR

In table 4 it can be observed that the participants exhibited an average heart rate of $135.5 \mathrm{bpm}$ in the Pilates mat based exercises sessions, which corresponded to $74 \%$ of the maximum rate, and $134 \mathrm{bpm}$ in the resistance exercise sessions, which corresponded to $72 \%$ of the maximum rate.

Table 4

Heart rates of all participants during Pilates mat based exercise and resistance exercise sessions

Pilates Resistance exercise

Average heart rate $\quad 125.4 \pm 12.8 \quad 114.1 \pm 19.3$

Average percentage of

maximal heart rate *

$74.2 \pm 4.7$

$72.4 \pm 8.7$

All values presented as mean \pm standard deviation

* Maximal heart rate as measured during repetition maximal testing

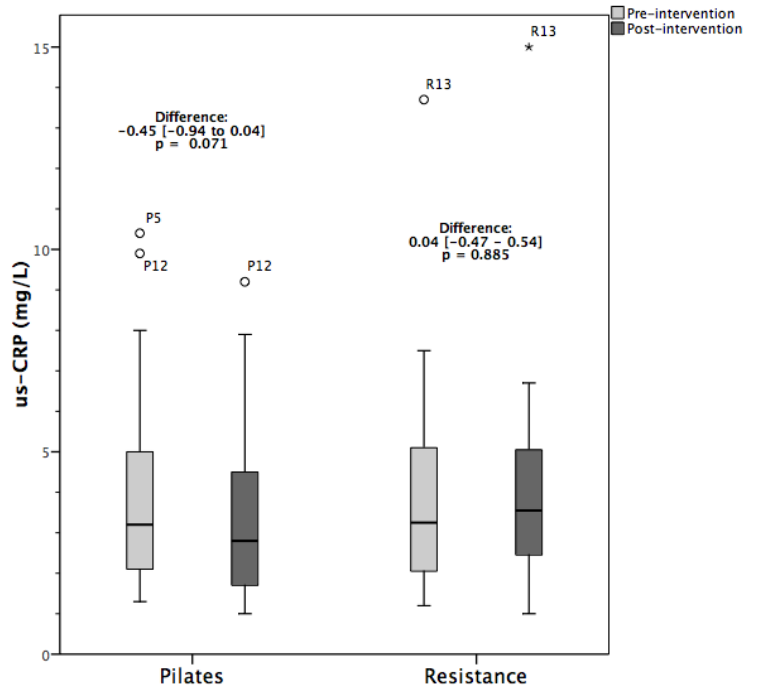

Figure 2. Comparison of hs-CRP (mg/L) before and after intervention in GP and GR. Difference is calculated as value (post - pre)-intervention and is presented as mean ( $95 \%$ confidence interval). P-value as calculated by paired t-test.
Figure 2 states the comparison of hs-CRP $(\mathrm{mg} / \mathrm{L})$ before and after intervention in GP and GR. It demonstrates that there was a trend in GP towards reduction of hs-CRP levels $(\mathrm{P}=0.071)$.

When comparing abdominal circumference before and after intervention in GP and GR (figure 3) it can be observed a significant reduction in GP $(p=0.001)$ and GR $(p=00: 26)$.

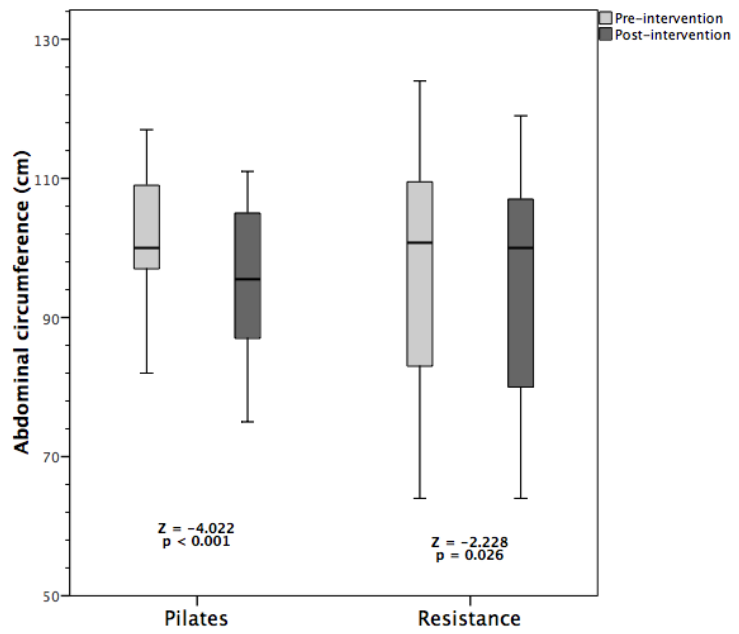

Figure 3. Comparison of abdominal circumference before and after intervention in GP and GR. P-value as calculated by Wilcoxon Sign-rank test.

As for BMI the comparison before and after intervention in GP and GR (figure 4) demonstrated a significant reduction in GP ( $p=$ 0.001).

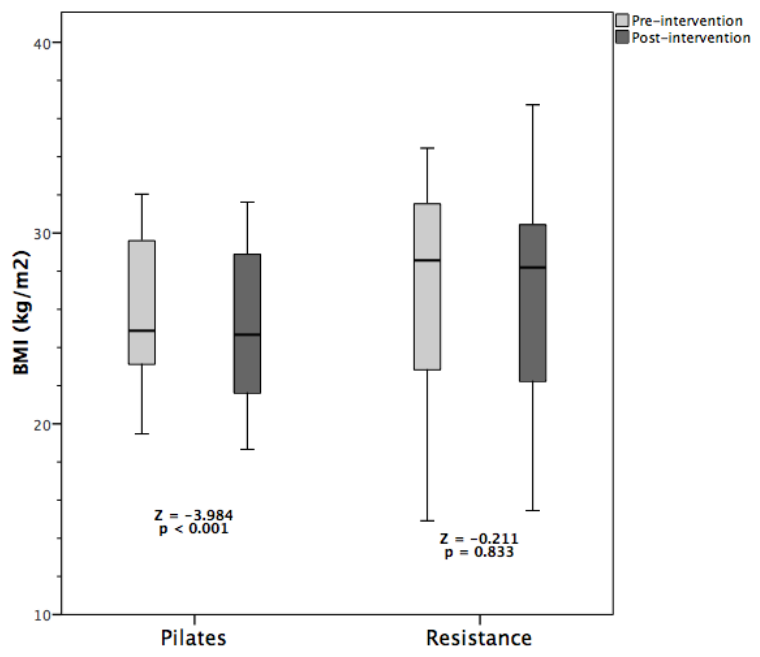

Figure 4. Comparison of BMI before and after intervention in GP and GR. P-value as calculated by Wilcoxon Sign-rank test. 


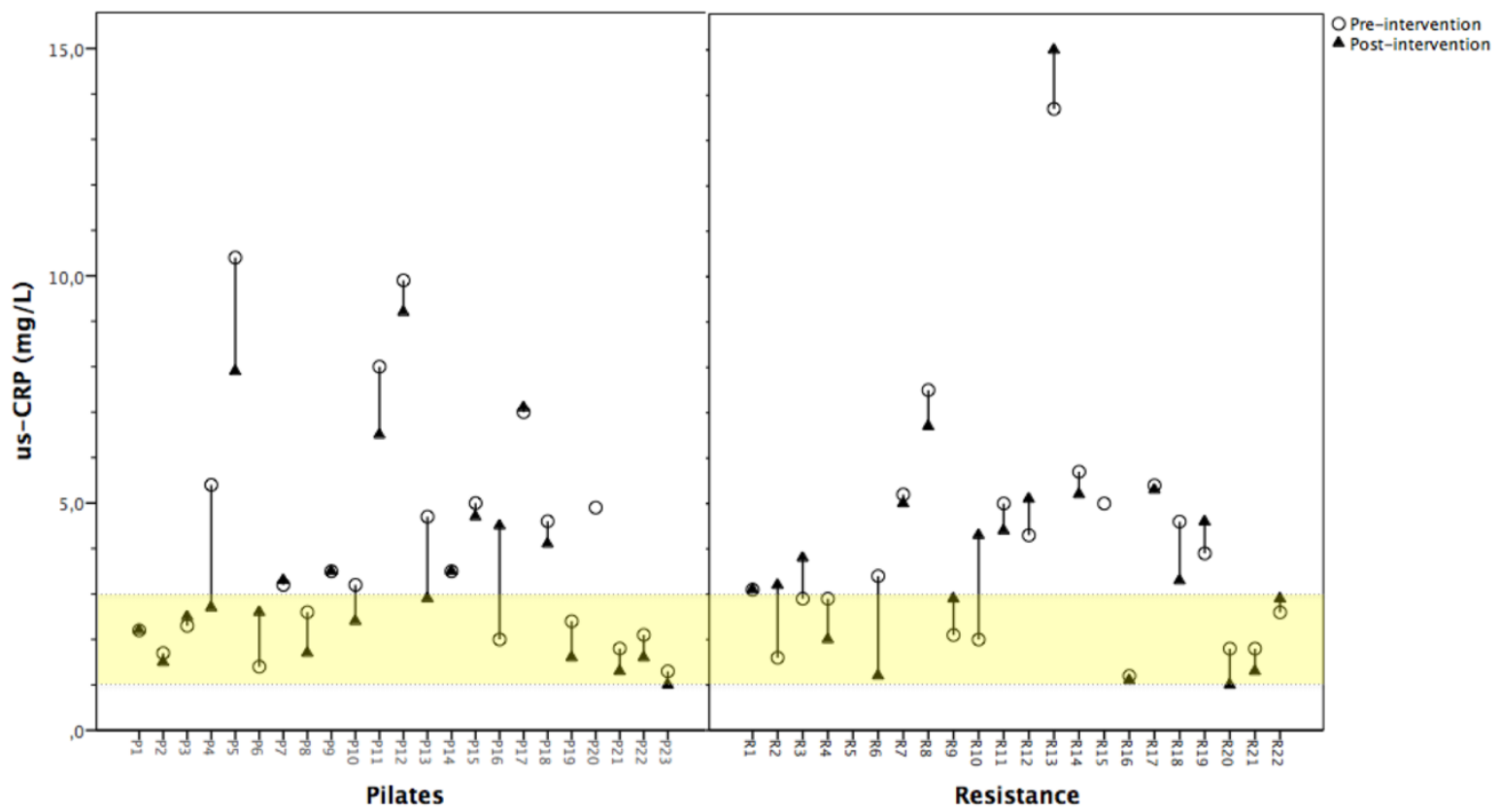

Figure 5. Summary of each subject's change in us-CRP $(\mathrm{mg} 7 / \mathrm{L})$ in all subjects
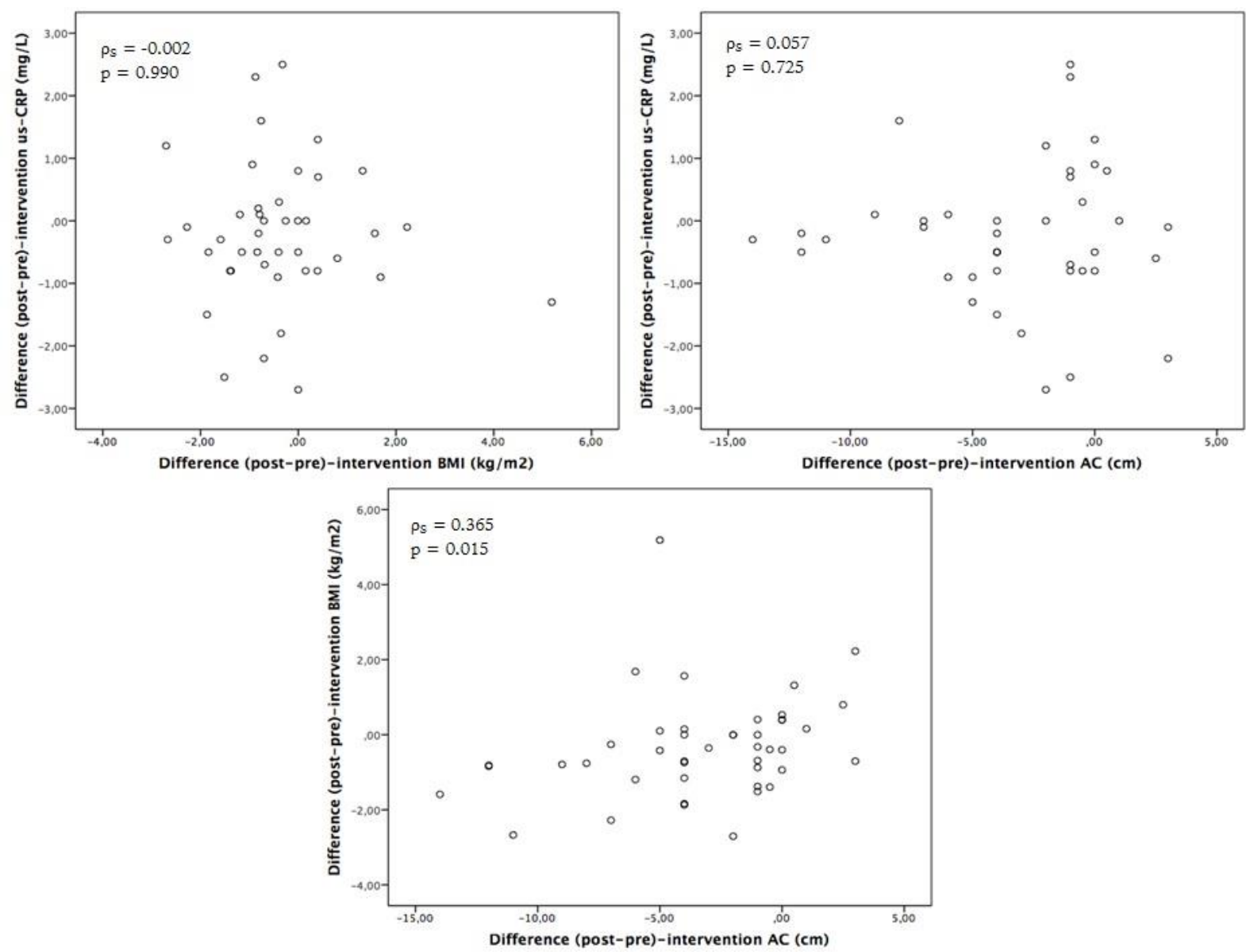

Figure 6. Scatter-plot comparing the difference (post-pre)-intervention values of us-CRP with AC and BMI. Data presented with Spearman correlation coefficient $\left(\rho_{s}\right)$ and respective p-values.

\section{DISCUSSION}

In the present study, it was demonstrated that the Pilates method was more effective than resistance exercise in reducing abdominal circumference and body mass index in the elderly when compared to resistance exercise. It was also shown there was no significant reduction of hsCRP in both groups, however, Pilates group had 
a tendency to decrease in this variable. It was also revealed a positive correlation between the reduction of $\mathrm{AC}$ and $\mathrm{BMI}$ post intervention. The existence of correlation between BMI and abdominal circumference in this study corroborates some works described by Blauth, Lara, Wagner, and Reichert (2008), and Licastro et al. (2005), which point to the existence of significant association between obesity and protein measurements.

Based on the findings of the review study performed by Calle and Fernandes (2010), the combination of strength and endurance training (ie, concurrent training) conducted in moderate volume and moderate to high intensity in older populations is the most effective way to improve both neuromuscular and cardiorespiratory functions. The authors believe that long term endurance training can reduce the basal levels of cytokines. This is important because certain cytokines play a role in glucose metabolism. In addition, exercise interventions that include strength training should be prescribed to frail elderly in order to improve the general physical condition of this population and to prevent disability.

Mavros et al. (2014), conducted a randomized study, being demonstrated by linear regression that the increase in muscle mass after progressive resistance training was associated with reductions in hs-CRP, indicating that the increase in lean body mass with anabolic exercise can potentially mediate reductions in systemic inflammation. Until recently, hs-CRP was believed to be produced exclusively by hepatocytes, i.e., in response to circulating interleukin-6 (IL-6) adipose. However, production of hs- CRP within the visceral and subcutaneous adipose tissue has also been reported. Thus, hs-CRP reductions in circulation can be influenced either directly or indirectly by the reduction of adipose tissue. In the study by Kim et al. (2014), it was shown that after Pilates training by young people, held for 60-70 minutes over a period of 8 weeks, body mass index decreased in both control groups, but with no significant difference. Thus, it is considered that it is necessary to develop a Pilates exercise program for de purpose of reducing obesity and improvement in lipid metabolism.

Lin et al. (2010) investigated the correlation between us-CRP level and body fat percentage in men. Individuals aged 40 to 88 years old were investigated, and high levels of us-CRP correlated with adiposity in both men and women. The authors believe that this correlation is most likely due to the production of the interleukin IL- 6 by the adipose tissue, although this variable was not assessed in the present study. Recent studies by Lin et al (2010) and Licastro et al (2005) indicate that IL-6 is also produced by adipocytes in vivo proportionally to individuals' lipid mass. Therefore, excess adiposity might increase IL- 6 expression and, consequently, hs-CRP levels. Thus, an increased level of hs-CRP associated with obesity might not be related to a strong inflammatory state. In addition, us-CRP level has been strongly correlated with the risk of cardiac events, reduced physical functioning, and other comorbidities in the elderly.

Sasaki et al. (2007) reported that metabolic disorders, including hs-CRP levels, represent the main factors that must be monitored in central obesity. Currently, most countries exhibit a high prevalence of obesity independent of age, which might cause several health problems, as discussed above. This increase in health problems could result in greater public health costs and an increase in comorbidities, thus reducing the functionality of the elderly and triggering other bodily disorders. Thus, controlling the hs-CRP levels in individuals with increased abdominal fat might represent an efficient approach to reducing atherogenic and cardiovascular risk.

According to Nicklas and Brinkley (2009), physical training is associated with adaptations in the skeletal muscle and immune cells, which may contribute to the lower levels of inflammatory biomarkers observed in physically active individuals. However, the inflammatory response is a complex phenomenon, and research has not elucidated which inflammatory biomarkers are the most important indicators of the effect of physical activity on the inflammatory state. 
Stewart et al. (2007) performed a comparative study of the influence of a 12-week resistance training program combined with aerobic training on hs-CRP and inflammatory cytokine levels in elderly and young individuals. The serum hs-CRP levels decreased with training in the inactive groups but did not differ in the active groups after training. In these two studies, the exercise programme combined strength and aerobic training and was associated with a significant reduction in hs-CRP levels; however, the duration of intervention was different, and the intensity and number of weekly sessions were not reported. The techniques used in the investigated treatments combined aerobic exercise with strength training, making it difficult to establish the efficacy of a particular method.

Another aerobic exercise programme was adopted in Lakka et al. (2005) study of healthy sedentary adults, who participated in a 20 -week training session on cycle ergometers that were individualised according to the participant's heart rate and oxygen consumption ratio. The authors found that the hs-CRP level decreased by approximately $1.3 \mathrm{mg} / \mathrm{L}$ in individuals with high baseline levels $(>3.0 \mathrm{mg} / \mathrm{L})$. It is worth noting that cycle ergometers represent an exercise method that both promotes a cardiovascular response from the aerobic exercise and strengthens the lower limb muscles. Therefore, this method might also combine strength and aerobic training.

A study by Campbell et al. (2008) investigated the effect of moderate-intensity aerobic exercise for 12 weeks on the serum hs-CRP levels of previously sedentary men and women aged 40 to 75 years old, with BMIs of 29.9 and 28.7, respectively. In that intervention study, which used aerobic exercise alone, the serum hs-CRP levels did not decrease.

According Cadore, Pinto, Bottaro, and Izquierdo (2014), subjects performed three training sessions a week, unlike previous studies, which performed two sessions per week (ie $30 \%$ ). The authors showed that a frequency of three times a week did not promote higher strength gain in healthy and well-trained elderly individuals in comparison to two times per week (22 vs. $20 \%$ respectively). These authors suggested that for elderly subjects, previously trained twice a week can be an ideal weekly frequency to increase muscle strength. Another factor related to Ground Pilates exercises which can influence the magnitude of strength adaptations in the elderly is the intra-session exercise sequence. In our study we opted for a frequency of twice a week, and during the sessions of ground Pilates protocol, the ground abdominal exercises were practiced continuously, so that it was maintained at elevated heart rate within the parameters of moderate exercise (60-70\%).

According to McArdle et al. (2008), the heart rate can be used to estimate energy consumption; recent studies have shown that heart rate and the oxygen consumption, and consequently the energy consumption, exhibit linear correlations with a wide scope of aerobic exercises. In addition to oxygen consumption, other factors that also influence the heart rate response to exercise include body posture, the exercised muscle groups, whether the exercise is continuous or intermittent, and whether the exercise is static or dynamic. Higher heart rates occur during upper limb exercises and when the muscles act statically. In the present study, all of the exercises performed in the Pilates mat based exercises protocol included contraction of the abdominal oblique and transverse muscles, pelvic floor muscles, and the multifidus and stabilisers of the shoulder girdle, which suggests that GP experienced a greater energy expenditure compared with GR.

The limitation of this study was not having found in the current literature studies on Pilates method or on markers of inflammation in the elderly. We also included the evaluation of the metabolic expenditure that was only made based on the measurement of heart rates. Moreover, another aspect that limited the present study was to control the frequency of the participants in the exercise sessions, who have given up or were unable to continue the training program for various reasons. 


\section{CONCLUSION}

In the present study, it was demonstrated that the Pilates method was more effective than resistance exercise in reducing abdominal circumference and body mass index, when compared to resistance exercise. It was also shown that there was no significant reduction of hs-CRP in both groups. However, in the Pilates group there was a tendency to decrease within this variable.

\section{Acknowledgments: \\ Nothing to declare}

\section{Conflict of interest:}

Nothing to declare

\section{Funding}

Nothing to declare

\section{REFERENCES}

Almeida, O. P. (1998). Mini exame do estado mental e o diagnóstico de demência no Brasil [Mini mental state examination and diagnosis of dementia in Brazil]. Arquivos de Neuro-Psiquiatria, 56, 605612.

Blauth, F., Lara, G. M., Wagner, S. C., \& Reichert, C. L. (2008) Associação entre fatores de risco cardiovascular e proteína C-reativa em mulheres idosas. J Bras Patol Med Lab, 44 (2), 83-88.

Calle, M.C., \& Fernandez, M.L. (2010). Effects of resistance training on the inflammatory response. Nutrition Research and Practice, 4(4):259-269. DOI: 10.4162/nrp.2010.4.4.259

Campbell, K. L., Campbell, P. T., Ulrich, C. M., Wener, M., Alfano, C. M., Foster-Schubert, K., ... McTiernan, A. (2008). No reduction in C-reactive protein following a 12-month randomized controlled trial of exercise in men and women. Cancer Epidemiology, Biomarkers \& Prevention, $17(7)$,

1714-1718.

https://doi.org/10.1158/1055-9965.EPI-080088

Cadore, E. L., Pinto, R. S., Bottaro, M., \& Izquierdo, M. (2014). Strength and endurance training prescription in healthy and frail elderly. Aging and Disease, 5(3), 183-195. http://doi.org/10.14336/AD.2014.0500183

Cesari, M., Penninx, B. W. J. H., Pahor, M., Lauretani, F., Corsi, A. M., Rhys Williams, G., ... Ferrucci, L. (2004). Inflammatory markers and physical performance in older persons: the InCHIANTI study. The Journals of Gerontology, 59(3), 242248.
Hyun, J., Hwangbo, K., \& Lee, C.-W. (2014). The effects of pilates mat exercise on the balance ability of elderly females. Journal of Physical Therapy Science, 26(2), 291-293. https://doi.org/10.1589/jpts.26.291

Kaesler, D. S., Mellifont, R. B., Kelly, P. S., \& Taaffe, D. R. (2007). A novel balance exercise program for postural stability in older adults: A pilot study. Journal of Bodywork and Movement Therapies, 11(1), 37-43. https://doi.org/10.1016/j.jbmt.2006.05.003

Kim, H.-J., Kim, J., \& Kim, C.-S. (2014). The effects of pilates exercise on lipid metabolism and inflammatory cytokines mRNA expression in female undergraduates. Journal of Exercise Nutrition \& Biochemistry, 18(3), 267-275. https://doi.org/10.5717/jenb.2014.18.3.267

Kopitzke, R. (2007). Pilates: a fitness tool that transcends the ages. Rehab Management, 20(28), 30-31.

Lakka, T. A., Lakka, H.-M., Rankinen, T., Leon, A. S., Rao, D. C., Skinner, J. S., ... Bouchard, C. (2005). Effect of exercise training on plasma levels of Creactive protein in healthy adults: the HERITAGE Family Study. European Heart Journal, 26(19), 2018-2025.

https://doi.org/10.1093/eurheartj/ehi394

Licastro, F., Candore, G., Lio, D., Porcellini, E., Colonna-Romano, G., Franceschi, C., \& Caruso, C. (2005). Innate immunity and inflammation in ageing: a key for understanding age-related diseases. Immunity \& Ageing: $I \& A, 2,8$. https://doi.org/10.1186/1742-4933-2-8

Lin, C.-C., Kardia, S. L., Li, C.-I., Liu, C.-S., Lai, M.-M., Lin, W.-Y., ... Li, T.-C. (2010). The relationship of high sensitivity C-reactive protein to percent body fat mass, body mass index, waist-to-hip ratio, and waist circumference in a Taiwanese population. BMC Public Health, 10, 579. https://doi.org/10.1186/1471-2458-10-579

Mavros, Y., Kay, S., Simpson, K. A., Baker, M. K., Wang, Y., Zhao, R. R., ... Fiatarone Singh, M. A. (2014). Reductions in C-reactive protein in older adults with type 2 diabetes are related to improvements in body composition following a randomized controlled trial of resistance training. Journal of Cachexia, Sarcopenia and Muscle, 5(2), 111-120. https://doi.org/10.1007/s13539014-0134-1

McArdle, W.D., Katch, F., Katch, V. L. (2008). Fisiologia do exercício: energia, nutrição e desempenho humano [Physiology of exercise: energy, nutrition, and human performance]. Rio de Janeiro: Guanabara Googan.

Miranda, L. B. \& Morais, P. D. C. (2006). Efeitos do método pilates sobre a composição corporal e flexibilidade [Effects of the Pilates method on the body composition and flexibility]. Revista Brasileira de Prescrição e Fisiologia do Exercício 3(13), 16-21.

Mottini, D. U., Cadore, E. L., \& Kruel, L. F. M. ( 2008) Efeitos do exercício na densidade mineral óssea 
$140 \mid$ MDS Pestana, EM Netto, MCS Pestana, VS Pestana, MI Schinoni

[Effects of exercise on the bone mineral density]. Motriz, 14(1), 85-95.

Muscolino, J. E., \& Cipriani, S. (2004). Pilates and the "powerhouse»-II. Journal of Bodywork and Movement Therapies, 8(2), 122-130. https://doi.org/10.1016/S1360-8592(03)000585

Nicklas, B. J., \& Brinkley, T. E. (2009). Exercise Training as a Treatment for Chronic Inflammation in the Elderly. Exercise and sport sciences reviews, 37(4), 165-170. https://doi.org/10.1097/JES.0b013e3181b7b3d 9

Panelli, C. \& De Marco, A. (2006) Método pilates de condicionamento do corpo [Pilates method for body conditioning]. São Paulo: Phorte.

Polito, M. D. \& Farinatti, P. T.V. (2003) Respostas de frequência cardíaca, pressão arterial e duploproduto ao exercício contra-resistência: uma revisão da literature [Heart rate, arterial pressure and double-product responses to resistance exercise: a literature review]. Revista Portuguesa de Ciências do Desporto, 3(1), 79-91.

Sasaki, J. E., Krause, M. P., Gama, M. P. R., Hallage, T., Buzzachera, C. F., Santos, M. G. dos, \& Silva, S. G. da. (2007). Influence of overall and abdominal adiposity on C-reactive protein levels in elderly women. Arquivos Brasileiros de Cardiologia, 89(4), 231-236. https://doi.org/10.1590/S0066782X2007001600004

Segal, N. A., Hein, J., \& Basford, J. R. (2004). The effects of Pilates training on flexibility and body composition: an observational study. Archives of
Physical Medicine and Rehabilitation, 85(12), 1977-1981.

Sekendiz, B., Altun, Ö., Korkusuz, F., \& Akın, S. (2007). Effects of Pilates exercise on trunk strength, endurance and flexibility in sedentary adult females. Journal of Bodywork and Movement Therapies, 11(4), 318-326. https://doi.org/10.1016/j.jbmt.2006.12.002

Stewart, L. K., Flynn, M. G., Campbell, W. W., Craig, B. A., Robinson, J. P., Timmerman, K. L., ... Talbert, E. (2007). The influence of exercise training on inflammatory cytokines and Creactive protein. Medicine and Science in Sports and Exercise, 39(10), 1714-1719. https://doi.org/10.1249/mss.0b013e31811ece1c

Vasques, A.C.J., Rosado, L.E.F.P. L, Rosado, G.P., Ribeiro, R.C.L., Franceschini, S.C.C., Geloneze, B. ... Oliveira, D.R. (2008). Diferentes aferiçôes do diâmetro abdominal sagital e do perímetro da cintura na predição do HOMA-IR. Sociedade Brasileira de Cardiologia.

Vasques, A. C. J., Rosado, L. E. F. P. de L., Rosado, G. P., Ribeiro, R. de C. L., Franceschini, S. do C. C., Geloneze, B., ... Oliveira, D. R. de. (2009). Different measurements of the sagittal abdominal diameter and waist perimeter in the prediction of HOMA-IR. Arquivos Brasileiros de Cardiologia, 93(5), 511-518. https://doi.org/10.1590/S0066$782 \mathrm{X} 2009005000001$

World Health Organization. (2008) Waist circumference and waist-hip ratio: report of a WHO expert consultation. Geneva: WHO 